\title{
PENGARUH R\&D EXPENDITURE TERHADAP \\ FIRM PERFORMANCE PADA PERUSAHAAN \\ YANG TERDAFTAR DI BEI PERIODE \\ 2003-2015
}

\author{
Agung Dharmawan Buchdadi \\ Fakultas Ekonomi Universitas Negeri Jakarta \\ e-mail: abuchdadi@unj.ac.id \\ Erlangga Oktafianto \\ Fakultas Ekonomi Universitas Negeri Jakarta \\ e-mail: erlanggaoktafianto@gmail.com \\ Umi Mardiyati \\ Fakultas Ekonomi Universitas Negeri Jakarta \\ e-mail: umi.mardiyati@gmail.com
}

\begin{abstract}
ABSTRAK
Tujuan dari penelitian ini adalah untuk menganalisa pengaruh $R \& D$ Expenditure terhadap Firm Performance pada perusahaan di Bursa Efek Indonesia (BEI) periode 2003-2015. Kinerja perusahaan diukur menggunakan ROA. Sedangkan $R \& D$ Expenditure dihitung menggunakan logaritma natural dari pengeluaran $R \& D$. Penelitian ini menggunakan data laporan keuangan 7 perusahaan yang terdaftar di Bursa Efek Indonesia (BEI). Penelitian ini menggunakan pendekatan analisis regresi panel dengan variabel dependen ROA. Penelitian ini menggunakan pertumbuhan perusahaan, utang, dan ukuran perusahaan sebagai variabel kontrol. Hasil penelitian ini menunjukan bahwa $R \& D$ Expenditure tidak berpengaruh terhadap Firm Performance pada perusahaan di Indonesia. Sedangkan variabel kontrol pertumbuhan perusahaan, utang, dan ukuran perusahaan berpengaruh signifikan terhadap Firm Performance.
\end{abstract}

Kata Kunci: $R \& D$ Expenditure, Kinerja Perusahaan, Pertumbuhan Perusahaan, Utang, Ukuran Perusahaan 


\section{PENDAHULUAN}

Saat ini, kemajuan teknologi dibuat oleh perusahaan di seluruh dunia dalam rangka meningkatkan posisi mereka di pasar, dalam hal efisiensi dan daya saing mereka. Perusahaan dalam rangka untuk mendapatkan keuntungan kompetitif terlibat dalam kegiatan penelitian dan pengembangan $(R \& D)$ yang mahal untuk mengembangkan inovasi oleh Thatcher dan Pingry (2009).

$R \& D$ memiliki peran penting untuk mengembangkan inovasi dalam produktivitas perusahaan agar tercapainya tujuan yang diharapkan oleh perusahaan. $R \quad \& \quad D$ nantinya diharapkan dapat menaikan produktivitas perusahaan, pertumbuhan dan kinerja jangka panjang setiap tahunnya menurut Pantagakis et al (2013). Untuk itu telah banyak perusahaan yang mau terlibat dalam kegiatan $R \& D$.

Jika ada peningkatan anggaran penelitian dan pengembangan, maka adanya kemungkinan kenaikan rasio pengembalian aset. Hal ini karena adanya hubungan positif antara kedua variabel tersebut. Dengan demikian kinerja perusahaan juga akan meningkat menurut Ghaffar dan Khan (2014).

Ekonomi pada umumnya menggunakan pengeluaran $R \& D$ sebagai indikator untuk mengukur inovasi input-output. Peningkatan secara terus menerus dari pendapatan dan keuntungan digunakan sebagai hasil akhir menurut Chan et al (2001). Jadi, berinvestasi dalam $R \& D$ menyiratkan menghasilkan aset penting bagi perusahaan meskipun, aset ini dapat dengan mudah hilang jika tidak dipelihara terus menerus. Untuk alasan ini, perusahaan perlu aliran investasi di $R$ $\& D$. Namun, ketika perusahaan melakukan berinvestasi dalam $R \& D$, mereka harus sadar akan fakta bahwa manfaat dari investasi $R \& D$ tidak didapat pada tahun di mana investasi berlangsung. Misalnya, sebuah perusahaan yang telah berinvestasi di $R \quad \& \quad D$ seharusnya tidak mengharapkan keuntungan atau peningkatan penjualan di tahun di mana investasi dikeluarkan.

Perusahaan manufaktur di negara-negara maju di Eropa seperti Belanda, Belgia dan Luxemburg telah banyak melakukan pengeluaran $R \& D$ untuk menaikan keuntungan perusahaan mereka menurut Beld (2014). Untuk di benua Asia, perusahaan-perusahaan yang terlihat telah melakukan pengeluaran $R \& D$ 

http://doi.org/10.21009/JRMSI

yaitu negara Turki, Cina, dan Jepang. Negara-negara maju telah memikirkan bahwa pengeluaran $R \& D$ nantinya akan menguntungkan mereka dimasa yang akan datang. Berbeda dengan negara berkembang yang belum memikirkan tentang pentingnya pengeluaran $R \& D$ untuk kemajuan perusahaan kedepannya. Penelitian sebelumnya menemukan bahwa pengeluaran $R \& D$ berkorelasi positif dengan kinerja perusahaan menurut Şişmanoĝlu dan Akçali (2016). Investasi dalam penelitian dan pengembangan berkontribusi secara signifikan terhadap penjualan, produktivitas dan keuntungan perusahaan menurut Hsu (2013). Selanjutnya, penelitian terdahulu telah menyimpulkan hubungan positif antara investasi $R \& D$ dan nilai pasar perusahaan oleh Artz et al (2010). Penelitian lain menemukan hasil yang bertentangan dengan penelitian sebelumnya yaitu bahwa $R$ \& $D$ memiliki hubungan negatif dengan kinerja perusahaan oleh Pantagakis et al (2013) dan Bouaziz (2016).

Selain pengeluaran $R \& D$ terdapat beberapa variabel yang mempunyai pengaruh terhadap kinerja perusahaan. Adapun variabel-variabel tersebut digunakan sebagai variabel kontrol. Ukuran perusahaan merupakan salah satu faktor yang mempengaruhi kinerja perusahaan. Terdapat pengaruh positif antara ukuran perusahaan dengan kinerja perusahaan menurut Pantagakis (2013). Ukuran perusahaan yang lebih besar cenderung melakukan penelitian dan pengembangan pada perusahaannya. Perusahaan besar memiliki kemudahan untuk melakukan penelitian dan pengembangan. Hal ini dikarenakan perusahaan besar memiliki kemampuan lebih untuk melakukan penelitian dan pengembangan dibanding perusahaan dengan total aset yang lebih kecil.

Kinerja perusahaan juga di pengaruhi oleh pertumbuhan perusahaan. Pertumbuhan perusahaan dengan kinerja perusahaan memiliki pengaruh positif menurut Pantagakis (2013). Hasil ini menjelaskan jika perusahaan dengan tingkat pertumbuhan yang tinggi biasanya bersedia untuk melakukan pengeluaran $R \& \mathrm{D}$ dengan harapan dengan melakukan penelitian dan pengembangan akan meningkatkan asset perusahaan sehingga adanya kenaikan pada kinerja perusahaan. 
Utang juga mempunyai pengaruh terhadap kinerja perusahaan. Semakin meningkatnya utang, maka hal tersebut berdampak pada profitabilitas perusahaan, karena sebagian dipergunakan untuk membayar pinjaman, dengan biaya bunga yang semakin besar, maka profitabilitas (EAT) akan semakin berkurang (karena sebagian untuk membayar bunga), maka hasil dari kinerja perusahaan akan semakin menurun menurut Pantagakis (2013). Maka dapat disimpulkan bahwa semakin tinggi kewajiban suatu perusahaan, maka akan semakin menurunkan hasil dari kinerja perusahaan tersebut. Utang memiliki hubungan negatif dengan kinerja perusahaan menurut Hsu (2013).

Tujuan dari penelitian ini adalah untuk meneliti pengaruh $R \& D$ expenditure terhadap firm performance pada perusahaan yang tercatat di Bursa Efek Indonesia (BEI) periode 2003-2015.

\section{TELAAH PUSTAKA}

\section{Kinerja Perusahaan (Firm Performance)}

Indikator berbasis akuntansi umumnya digunakan untuk mengukur kinerja perusahaan dan saham oleh investor dan analis keuangan secara teratur untuk mengukur kinerja perusahaan. Oleh karena itu, indikator ini telah dianggap sebagai kriteria yang lebih baik mengukur kinerja perusahaan. Selain itu, memungkinkan objektivitas saat mengukur dan membandingkan kinerja perusahaan yang berbeda menurut Sher dan Yang (2005).

Setiap kategori indikator berbasis akuntansi digunakan untuk memenuhi aspirasi dari setiap kelompok pemangku kepentingan. Selain itu, terdapat cara lain yang berguna untuk membantu menentukan suatu perusahaan berkinerja memuaskan bila dibandingkan dengan pesaingnya. Ada juga yang digunakan untuk mengukur kinerja manajemen perusahaan, untuk menilai apakah suatu perusahaan memiliki peluang investasi serta untuk mengevaluasi kinerja perusahaan terhadap pesaingnya menurut Wood dan Sangster (2002).

Selain itu, berdasarkan indikator akuntansi berguna dalam beberapa cara lain atau untuk beberapa tujuan lainnya. Misalnya berguna ketika menilai kemampuan perusahaan untuk membayar utang-utangnya, ketika mengevaluasi 
keberhasilan manajerial perusahaan dan ketika menilai kemampuan perusahaan sesuai peraturan perundang-undangan menurut Barnes (1987). Berdasarkan indikator akuntansi juga digunakan untuk mengukur kinerja perusahaan secara umum dalam hal volume fisik seperti pendapatan, keuntungan serta nilai tambah Mahato (2011).

Dalam penelitian ini indikator profitabilitas adalah ROA (Return On Assets). Rasio ini digunakan untuk mengukur laba perusahaan dalam kaitannya dengan semua sumber daya lain yang telah digunakan ke dalam bisnis. Rasio ini menunjukkan penghasilan pendapatan perusahaan dari aset yang diinvestasikan (utang dan ekuitas) dan memberikan informasi kepada investor tentang efektivitas perusahaan. ROA dihitung dengan membagi EBIT (Earning Before Interest and Tax) dengan Total Asset.

\section{Pengeluaran R \& D ( R \& D Expenditure $)$}

Berdasarkan Standar Akuntansi Keuangan (SAK) No. 19 menyatakan pengertian riset dan pengembangan. Riset (research) adalah penelitian orisinil dan terencana yang dilaksanakan dengan harapan memperoleh pembaruan pengetahuan dan pemahaman teknis atas ilmu yang baru. Pengembangan (development) adalah penerapan temuan riset atau pengetahuan lainnya pada suatu rancangan produksi bahan baku, alat, produk, proses, sistem, atau jasa yang sifatnya baru atau yang mengalami perbaikan yang substansial, sebelum dimulainya produksi komersial dan pemakaian.

$R \& D$ dalam arti luas adalah penggunaan usaha kreatif dan pengetahuan yang dilakukan sistematis berdasarkan dalam aplikasi baru dalam rangka meningkatkan pengetahuan ilmiah dan teknis. Dalam pengertian arti sempit $R \&$ $D$ adalah studi sistematis dan produktif bagi produk baru dan proses produksi baru dalam bisnis menurut Barutçugil (1981). Ekonomi pada umumnya menggunakan pengeluaran $R \& D$ sebagai indikator untuk mengukur inovasi input-output. Peningkatan pendapatan dan keuntungan secara terus menerus digunakan sebagai hasil akhir menurut Chan (2001). 


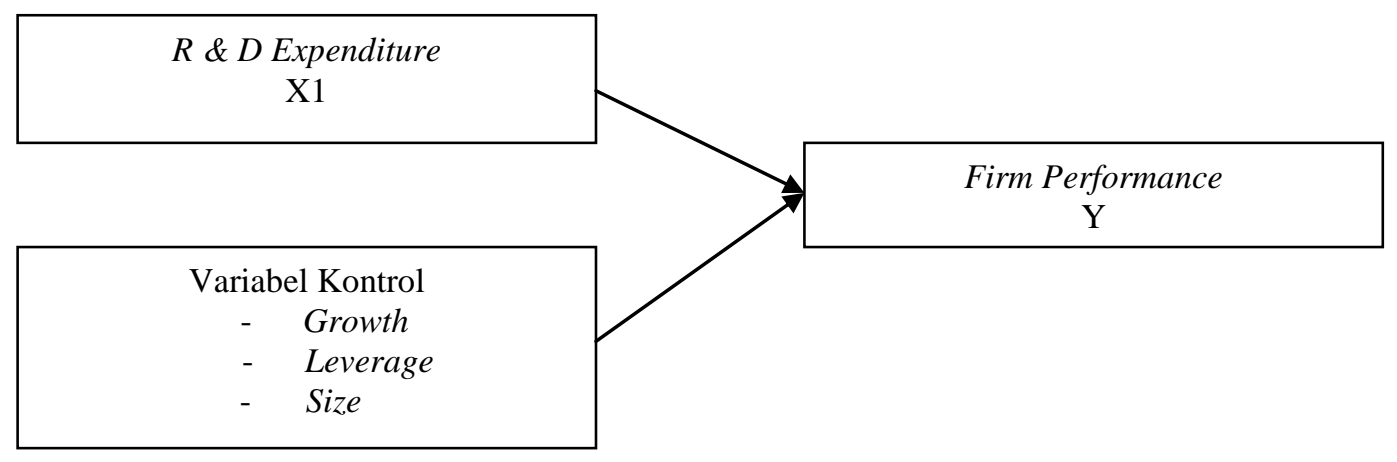

Gambar 1. Kerangka Penelitian

Sumber : Data diolah peulis (2017)

\section{Hipotesis}

Berdasarkan kajian pustaka dan kerangka teoritik diatas, maka dirumuskan hipotesis sebagai berikut:

$\mathrm{H}_{1} \quad: R \& D$ Expenditure memiliki pengaruh yang signifikan terhadap Firm Performnce.

\section{METODE PENELITIAN}

\section{Objek dan Ruang Lingkup Penelitian}

Objek yang diteliti pada penelitian ini adalah perusahaan yang terdaftar di Bursa Efek Indonesia (BEI) tahun 2003-2015. Dengan data yang terdiri atas $R \&$ $D$ Expenditure, pertumbuhan perusahaan (Growth), utang (leverage), ukuran perusahaan (Size), dan kinerja perusahaan (Firm Performance) yang diproksikan dengan $R O A$.

\section{Metode Penelitian}

Metode penelitian ini adalah metode asosiatif yang bertujuan untuk mengetahui pengaruh $R \& D$ expenditure sabagai variabel independen dan firm performance sebagai variabel dependen pada perusahaan di Indonesia periode 2003-2015.

\section{Populasi dan Sampling}

Populasi penelitian ini adalah perusahaan yang terdaftar di Bursa Efek Indonesia (BEI) periode 2003-2015. Metode pengambilan sample dalam 
penelitian ini adalah Purposive Sampling yaitu teknik sampling dengan melakukan pertimbangan dan batasan tertentu sehingga sample yang dipilih relevan dengan tujuan penelitian. Berdasarkan teknik Purposive Sampling, maka sample yang diambil adalah perusahaan yang memiliki kriteria sebagai berikut:

1. Perusahaan yang terdaftar di Bursa Efek Indonesia (BEI) periode 2003-2015.

2. Perusahaan melaporkan laporan keuangan dan laporan tahunan dalam periode 2003-2015.

3. Perusahaan yang melakukan pelaporan pengeluaran $R \& D$ dalam periode 2003-2015. Pada periode tersebut terdapat banyak perusahaan yang terdaftar pada Bursa Efek Indonesia (BEI), tetapi hanya sedikit perusahaan yang melaporkan pengeluaran $R \& D$. Sample yang diambil hanya perusahaan yang melaporkan pengeluaran $R \& D$ pada periode 2003-2015 tetapi, hanya yang melaporkan pengeluaran $R \& D$ secara berturut-turut pada setiap tahunnya.

4. Laporan keuangan dan laporan tahunan disajikan secara lengkap, termasuk penjelasan mengenai $R \& D$ expenditure.

Berdasarkan kriteria diatas, maka terpilih sebanyak 7 sampel perusahaan di Indonesia periode 2003-2015.

Tabel 1. Daftar Nama Perusahaan

\begin{tabular}{|c|c|c|c|}
\hline No. & Nama Perusahaan & Periode Tahun & Jumlah Tahun \\
\hline 1 & PT Unilever Indonesia Tbk. & $2003-2015$ & 13 Tahun \\
\hline 2 & $\begin{array}{l}\text { PT Telekomunikasi Indonesia } \\
\text { (Persero) Tbk. }\end{array}$ & $2005-2015$ & 11 Tahun \\
\hline 3 & PT Biofarma (Persero) & $2008-2014$ & 7 Tahun \\
\hline 4 & PT Kimia Farma (Persero) Tbk. & $2010-2015$ & 6 Tahun \\
\hline 5 & PT Pyridam Farma Tbk & $2010-2015$ & 6 Tahun \\
\hline 6 & PT Kalbe Farma Tbk. & $2010-2015$ & 6 Tahun \\
\hline 7 & PT HM Sampoerna Tbk. & $2011-2015$ & 5 Tahun \\
\hline
\end{tabular}

\section{Operasionalisasi Variabel Penelitian}

\section{Variabel Dependen}

Variabel Dependen dalam penelitian ini adalah firm performance. Indikator akuntansi berbasis profitabilitas yang digunakan untuk mengukur kinerja perusahaan dalam rangka untuk mengajarkan pemangku kepentingan tentang apakah suatu perusahaan berkinerja memuaskan dari segi profitabilitas. 
Rumus yang dapat digunakan untuk mengukur firm performance adalah ROA (Return On Assets) pada tahun selanjutnya setelah perusahaan melakukan $R \&$ $D$.

$$
\mathrm{ROA}_{\mathrm{t}+1}=\frac{\text { EBIT }(\text { Earning Before Interest and Tax })_{\mathrm{t}+1}}{\text { Total Asset }_{t+1}}
$$

\section{Variabel Independen}

Variabel Independen dalam penelitian ini adalah $R \& D$. Indikator yang dapat digunakan untuk mengukur pengeluaran $R \& D$ adalah $R \& D$ Expenditure pada tahun dimana biaya $R \& D$ dibebankan.

$R \& D$ Expenditures $t_{t}=\operatorname{Ln}(R \& D \text { Ependitures in the year })_{t}$

\section{Variabel Kontrol}

\subsection{Pertumbuhan Perusahaan (Growth)}

Pertumbuhan perusahaan adalah perusahaan yang mengalami peningkatan pertumbuhan dari tahun ke tahun. Pertumbuhan perusahaan (Growth) dapat dihitung dengan cara:

$$
\text { Growth }_{\mathrm{t}}=\frac{\text { Total Asset }_{t}-\text { Total Asset }_{t-1}}{\text { Total Asset }_{t-1}}
$$

\subsection{Utang (Leverage)}

Utang (leverage) mengukur seberapa jauh perusahaan dibiayai oleh utang. Leverage dapat dihitung dengan cara:

$$
\text { Leverage }_{t}=\frac{\text { Total Debt }_{t}}{\text { Total Asset }_{t}}
$$

\subsection{Ukuran Perusahaan (Size)}

Ukuran perusahaan adalah besar kecilnya nilai buku dari jumlah aktiva yang dimiliki oleh perusahaan dalam waktu tertentu. Dalam penelitian ini ukuran perusahaan dapat dihitung dengan cara:

$$
\text { Size }_{\mathrm{t}}=\operatorname{Ln}(\text { Total Asset })_{t}
$$




\section{HASIL DAN PEMBAHASAN}

\section{Penentuan Teknik Analisis Data Panel}

\section{Uji F (Chow)}

Untuk melakukan Uji Chow pada analisis ini menggunakan Redundant Fixed Effects Tests yang telah disediakan oleh software Eviews 9. Uji Chow bertujuan untuk mengetahui apakah model Pooled OLS atau fixed effects model (FEM), model yang terbaik untuk digunakan dalam sebuah model regresi.

Hasil dari Uji Chow atau Uji Redundant Fixed Effects Tests pada penelitian ini adalah sebagai berikut :

Tabel 2. Hasil Redundant Fixed Effects Tests

\begin{tabular}{|c|c|c|c|}
\hline \multicolumn{4}{|c|}{$\begin{array}{l}\text { Redundant Fixed Effects Tests } \\
\text { Equation: FIX } \\
\text { Test cross-section fixed effects }\end{array}$} \\
\hline Effects Test & Statistic & d.f. & Prob. \\
\hline Cross-section F & 65.793077 & $(6,43)$ & 0.0000 \\
\hline Cross-section Chi-square & 125.305228 & 6 & 0.0000 \\
\hline
\end{tabular}

Sumber: Output Eviews 9, data diolah Peneliti (2017)

Berdasarkan hasil pengujian yang ditunjukkan pada tabel 2, diketahui probabilitas dari uji statistik $\mathrm{F}$ adalah sebesar 0.0000 lebih kecil dari 0,05 sehingga dengan tingkat keyakinan $95 \%$ dapat menolak $\mathrm{H}_{0}$. Hasil pengujian ini menunjukkan bahwa model yang baik untuk digunakan dalam penelitian ini adalah fix effect model dibandingkan dengan common effet model. Sehingga perlu dilakukan pengujian model selanjutnya yaitu Uji Hausman.

\section{Uji Hausman}

Pengujian ini merupakan uji akhir untuk memilih metode apa yang tepat untuk digunakan dalam penelitian ini, metode fixed effect atau random effect. Uji hausman menggunakan Correlated Random Effects - Hausman Test yang telah disediakan oleh software Eviews 9. Adapun hasil dari Uji Hausman atau Correlated Random Effects - Hausman Testpada penelitian adalah pada tabel 3 berikut ini: 
Tabel 3. Hasil Correlated Random Effects - Hausman Test

Correlated Random Effects - Hausman Test

Equation: RANDOM

Test cross-section random effects

\begin{tabular}{lrrr}
\hline \hline Test Summary & Chi-Sq. Statistic & Chi-Sq. d.f. & Prob. \\
\hline \hline Cross-section random & 28.330766 & 4 & 0.0000 \\
\hline \hline
\end{tabular}

Sumber: Output Eviews 9, data diolah Peneliti (2017)

Berdasarkan hasil pengujian pada tabel 3 menunjukkan bahwa uji Hausman signifikan dengan Chi-square statistik sebesar 28.330766 dan nilai p sebesar 0.0000. Oleh karena itu $\mathrm{H}_{0}$ diterima sehingga dapat disimpulkan pada penelitian ini model yang terbaik yang digunakan dalam penelitian ini adalah Fix Effect Model (FEM).

\section{Uji Multikolinearitas}

Uji multikolinearitas memiliki tujuan untuk menguji apakah dalam model regresi ditemukan adanya hubungan antara variabel yang tinggi dan sempurna. Keberadaan multikolinearitas dalam suatu model regresi dapat dilihat dari korelasi antara dua variabel independen yang lebih dari 0,90 .

Berdasarkan hasil pengujian pada tabel 4 tidak ditemukan korelasi antara variabel independen yang lebih dari 0,90 sehingga dapat disimpulkan bahwa data sampel penelitian yang digunakan tidak terdapat multikolinearitas.

Tabel 4. Hasil Uji Multikolinearitas

\begin{tabular}{ccccc}
\hline & R\&D & GROWTH & LEVERAGE & SIZE \\
\hline R\&D & 1.000 .000 & 0.168427 & 0.196206 & 0.046098 \\
GROWTH & 0.168427 & 1.000 .000 & -0.143097 & -0.008507 \\
LEVERAGE & 0.196206 & -0.143097 & 1.000 .000 & 0.349842 \\
SIZE & 0.046098 & -0.008507 & 0.349842 & 1.000 .000 \\
\cline { 2 - 5 } Sumber: Output Eviews 9, data diolah Peneliti (2017) & &
\end{tabular}

\section{Uji Hipotesis}

\section{Uji Signifikansi Parameter Individual (Uji t)}

Uji statistik t dilakukan untuk menunjukkan seberapa signifikan pengaruh satu variabel independen terhadap variabel dependen, dengan asumsi variabel 
yang lainnya konstan.

Taraf kesalahan atau nilai signifikansinya $(\alpha)$ sebesar $1 \%, 5 \%$ dan $10 \%$ atau sebesar 0,01, 0,05 dan 0,10. Hasil dari Uji Statistik t dengan Fix Effect Model pada penelitian ini adalah pada tabel 5 berikut ini:

Tabel 5. Hasil Uji Statistik t

Dependent Variable: ROA

Method: Panel Least Squares

Date: 07/19/17 Time: 22:52

Sample: 20032015

Periods included: 13

Cross-sections included: 7

Total panel (unbalanced) observations: 54

\begin{tabular}{crrrr}
\hline \hline Variable & Coefficient & Std. Error & t-Statistic & Prob. \\
\hline \hline C & 1.103310 & 0.206907 & 5.332392 & 0.0000 \\
R_D & 0.003437 & 0.006614 & 0.519650 & 0.6060 \\
GROWTH_ & 0.088898 & 0.048041 & 1.850457 & 0.0711 \\
LEVERAGE & 0.135508 & 0.057669 & 2.349764 & 0.0234 \\
SIZE__ & -0.058011 & 0.012637 & -4.590609 & 0.0000 \\
\hline \hline
\end{tabular}

Sumber: Output Eviews 9, data diolah Peneliti (2017)

Persamaan regresi data panel yang dihasilkan dengan Fixed Effect Model adalah :

\section{ROA $=1,103310+0,003437$ RD + 0,088898 GTH + 0,135508 LEV - 0,058011 SIZE}

\section{Koefisien Determinasi $\left(\mathbf{R}^{2}\right)$}

Koefisien determinasi dijadikan sebagai ukuran seberapa jauh kemampuan suatu model dalam menjelaskan variabel dependen (Ghozali, 2013:59).

Berdasarkan hasil regresi Fix Effects Model pada tabel 5 menunjukkan bahwa nilai adjusted $R$-squared sebesar 0,9730 yang berarti variabel-variabel indepen mampu menjelaskan variasi variabel dependen sebesar 97,30 persen, sedangkan sisanya 2,70 persen dijelaskan oleh variabel lain yang tidak digunakan dalam penelitian ini.

\section{Pengaruh $R \& D$ Expenditure Terhadap Kinerja Perusahaan}

Pada tabel 5 nilai probabilitas $R \& D$ sebesar 0,6060>0,05 sehingga variabel $R$ \& $D$ tidak berpengaruh terhadap kinerja perusahaan. Hal ini menunjukan bahwa Hipotesis pertama $\left(\mathrm{H}_{1}\right)$ yang menyatakan bahwa $R \& D$ 
Expenditure berpengaruh signifikan terhadap kinerja perusahaan ditolak. Hasil ini bertentangan dengan hasil penelitian sebelumnya oleh Cheng (2013) dan Tuna dan Yildiz (2016), yang menyatakan bahwa $R \& D$ Expenditure memiliki pengaruh positif dan signifikan terhadap kinerja perusahaan.

Hasil penelitian ini sejalan dengan hasil penelitian yang telah dilakukan sebelumnya oleh Konak dan Kendirli (2014) yang menyatakan tidak ada pengaruh antara $R \& D$ Expenditure terhadap kinerja perusahaan. Pada saat perusahaan melakukan $R \& D$ Expenditure tidak diimbangi dengan kenaikan penjualan dari produk dari perusahaan tersebut.

\section{Pengaruh Variabel Kontrol Growth, Leverage, dan Size Terhadap Kinerja Perusahaan}

Pada tabel 5 variabel kontrol growth, leverage, dan size memiliki pengaruh signifikan terhadap kinerja perusahaan. Untuk growth memiliki pengaruh positif signifikan terhadap kinerja perusahaan pada tingkat signifikansi sebesar $10 \%$. Hasil ini sesuai dengan hasil penelitian sebelumnya oleh Pantagakis et al (2013) yang menyatakan growth memiliki pengaruh positif dan signifikan terhadap kinerja perusahaan. Hubungan positif antara growth karena perusahaan dengan growth yang tinggi memiliki nilai investasi dalam jumlah besar, terutama pada aktiva tetap yang memiliki umur ekonomis lebih dari satu tahun. Perusahaan ini cenderung untuk menahan labanya demi membiayai $R \& D$ expenditure yang besar dalam rangka melakukan ekspansi bisnis, sehingga perusahaan dengan growth yang tinggi akan memiliki kinerja yang baik pula menurut Bouaziz (2016).

Untuk leverage memiliki pengaruh positif signifikan terhadap kinerja perusahaan pada tingkat signifikansi sebesar 5\%. Hasil ini sesuai dengan hasil penelitian sebelumnya yang menyatakan leverage memiliki pengaruh positif dan signifikan terhadap kinerja perusahaan. Hubungan positif antara leverage disebabkan karena penggunaan utang yang dapat membantu dana untuk proyek $R$ $\& D$ didalam operasional perusahaan. Size memiliki pengaruh negatif signifikan terhadap kinerja perusahaan pada tingkat signifikansi sebesar $1 \%$. Menurut Theacini dan Wisadha (2014) ukuran perusahaan merupakan salah satu variabel yang penting dalam pengelolaan perusahaan. Semakin besar ukuran perusahaan 
maka semakin kompleks perusahaan dalam mengelola dananya secara efektif dan efisien. Oleh sebab itu, perusahaan menjadi lebih rumit untuk mengelola dananya dengan baik dan tepat.

\section{KESIMPULAN DAN SARAN}

\section{Kesimpulan}

Penelitian ini dilakukan dengan tujuan untuk mengetahui secara empiris mengenai pengaruh $R \& D$ expenditure terhadap kinerja perusahaan dengan pengaruh growth, leverage, dan size sebagai variabel kontrol. Penelitian dilakukan pada perusahaan yang terdaftar di Bursa Efek Indonesia (BEI) periode 2003-2015. Dari 291 perusahaan terdaftar di Bursa Efek Indonesia (BEI) yang memiliki data mengenai $R \& D$ expenditure sebanyak 7 perusahaan. Hasil penelitian ini $R \& D$ expenditure tidak memiliki pengaruh terhadap kinerja perusahaan yang diproksikan dengan Return On Asset (ROA). Variabel kontrol growth dan leverage memiliki pengaruh positif sedangkan size memiliki pengaruh negatif. Hal ini menandakan bahwa dana yang dikeluarkan oleh perusahaan untuk $R \& D$ bukan merupakan alasan pada kenaikan kinerja perusahaan karena dengan melakukan $R \& D$ expenditure yang tidak diikuti oleh growth, leverage, dan size yang tepat maka $R \& D$ tidak berpengaruh terhadap kinerja perusahaan.

\section{Saran}

Penulis berharap penelitian yang telah dilakukan dapat menginspirasi penelitian-penelitian selanjutnya yang berkaitan dengan topik penelitian yang dilakukan ini. Penulis menyadari penelitian ini memiliki banyak kekurangan. Oleh sebab itu, penulis menyarankan untuk penelitian selanjutnya, yaitu:

a. Untuk mengidentifikasi proksi lain dari kinerja perusahaan seperti ROE dan tobins'q.

b. Menambahankan populasi yang bukan hanya dari perusahaan di Bursa Efek Indonesia namun bursa efek dari perusahaan negara lain agar penelitian selanjutnya mendapatkan hail yang lebih akurat dari penelitian sebelumnya.

\section{DAFTAR PUSTAKA}


Artz, Kendall W, et al. (2010) "A Longitudinal Study of the Impact of R \& D, Patens, and Product Innovationon Firm Performance.” Journal Prod Innov Manag., vol. 27, hal. 725-740.

Barnes, P. (1987). "The Analysis and Use Of Financial Ratios: A Review Article”. Journal of Business Finance \& Accounting, 14(4), 449-461.

Barutçugil, D.S. (1981). Teknolojik Yenilik ve Arastırma Gelistirme Yönetimi, Bursa, Bursa Basımevi.

Beld, Bart. (2014). "The Effects of R\&D investment on firm performance." Journal IBA Bachelor Conference, hal. 1-9.

Bouaziz, Zied. (2016). "The Impact of R\&D Expenses on Firm Performance: Empirical Witness from the Bist Technology Index." Journal of Business Theory and Practice., Vol. 4, No. 1, hal. 51-60.

Chan, L., Lakonishok, J., \& Sougiannis, T. (2001). "The stock market valuation of research \& development expenditures”. Journal of Finance, 56(6), 24312456.

Cheng, Min-Tsung. (2013). "The moderating effects of chief executive officer (CEO) duality on the relationship between research and development ( $\mathrm{R}$ and D) spending and firm performance." African Journal of Business Management. Vol. 7(8), hal. 631-640.

Ghaffar, Aimen dan Khan, Waseem Ahmed. (2014). "Impact of Research and Development on Firm Performance.” International Journal of Accounting and Financial Reporting. Vol. 4, No. 1, hal. 357-367.

Ghozali, I. (2013). Analisis Multivariat dan Ekonometrika Teori, Konsep, dan Aplikasi dengan Eviews 8. Semarang: Badan Penerbit Universitas Diponegoro.

Hsu, Dr. Hsueh-En. (2013) “The Moderating Effects Of Leverage And Ownership Structure On Firm Performance.” South East Asia Journal of Contemporary Business, Economics and Law. Vol. 2, hal. 73-76.

Konak, Fatih dan Kendirli, Selcuk. (2014). "Impact of R\&D Expenses on Firm Performance: Empirical Evidence from the BIST Information Technology 
Index." Procedia Journal of Economics and Business Administration, hal. 192-197.

Mahato, M. (2011). "Performance Analysis of High, Medium and Low Companies in Indian Pharmaceuticals Industry". IUP Journal of Management Research, 10(3), 52-70.

Pantagakis, E., et al. (2013). "R\&D investments and firm performance : An Empirical Investigation of the High Technology Sector (Software and Hardware) in the E.U. International Journal of Accounting, hal. 1-20.

Sher, P. J., dan Yang, P. Y. (2005). "The effects of innovative capabilities and R\&D clustering on firm performance: the evidence of Taiwan's semiconductor industry". Journal of Technovation, 25(1), 33-43.

Şişmanoĝlu, Elçin dan Akçali, Burçay Yaşar. (2016). “The Effect Of Innovation On Financial Performance Of Some Information And Technology Companies In Turkey.” Journal Ekonometri ve İstatistik, Vol. 24, hal. 8293.

Thatcher, M., dan D. Pingry. (2009). "Optimal Policy for Software Patents: Model and Comparative Implications". Journal of Management Information Systems, 26, pp. 103-134.

Theacini, D. A dan Wisadha, I. S. (2014). Pengaruh Good Corporate Governance, Kualitas Laba dan Ukuran Perusahaan Pada Kinerja Perusahaan. Jurnal Akuntansi Universitas Udayana, Vol. 7, No. 3, 733-746.

Tuna, Gülfen dan Yildiz, Şule. (2016). “The Impact Of Operating Expenditures On Firm Performance In Turkey: Evidence From Technology Sector.” Journal Original Scientific, Vol. 62, No 4, hal. 1-15.

Wood, F., dan Sangster. (2002). A. Business Accounting 2 (9 ed.). Harlow: Financial Times/Prentice Hall.

www.idx.co.id ( Diakses 8 April 2017) 